\title{
Assessment of Oral Health Needs, Functional Ability, Barriers and Utilization of Oral Health Services among the Inmates of Old Age Homes of Hyderabad
}

\section{Reddy PP, Anjum MS, Rao KY, Monica M, Akula S and Deepthi N*}

Sri Sai College of Dental Surgery, Public Health Dentistry, Vikarabad, Telangana, 501102, India

\begin{abstract}
Background: The proportion of older people continues to grow worldwide, especially in developing countries. Approximately 600 million people are aged 60 years and over, and this number will double by 2025 .

Methods: A cross-sectional study was conducted among 323 inmates of old age homes who were above the age of 55 years in Hyderabad city. A structured 16 item questionnaire which assessed utilization and barriers of oral health care services and functional ability questionnaire was used to collect data in an interview method and dentition status was recorded using WHO 1997 proforma. The collected data were subjected to statistical analysis using SPSS version 21.0.

Results: Among 323 participants, 89 were males and 243 were females. About $86 \%$ experienced dental problems, among which $35 \%$ complained of dental pain and $22 \%$ of missing teeth. Of them, $78 \%$ did not receive any dental treatment and $66 \%$ felt there is a need for oral care at old age. Approximately $48 \%$ felt there is no access to treatment in the old age homes.
\end{abstract}

Conclusion: Limited access to oral care was one of the most commonly reported barriers to utilization of dental services. There is a need for oral health promotion and intervention at the old age home.

Keywords: Institutionalized elderly; Functional ability; Oral health needs; Barriers

\section{Introduction}

The proportion of older people continues to grow worldwide, especially in developing countries. Approximately 600 million people are aged 60 years and over, and this number will double by 2025. By 2050 , it will be 2 billion, $80 \%$ living in developing countries [1]. India has around 100 million elderly at present and the number is expected to increase by 323 million, constituting $20 \%$ of the total population, by 2050 . Chronic diseases such as diabetes, cardiovascular diseases, hypertension, and cancer are fast becoming the leading causes of disability and mortality [2]. Oral health and general health are interlinked. Old age homes are set up for elderly persons who cannot be taken care of by their children for various reasons or the elderly join willingly. The residents of old age homes have poor oral health as they depend on the caregivers for daily hygiene maintenance. Moreover, studies have proven that the dental status of elderly living in old age homes is poor. Poor oral health can limit their food choices and diminish the pleasure of eating. The dental needs of the elderly are changing and growing.

Berk, et al. reported that nearly $30 \%$ of this population have chronic health problems that limit daily activities. It is likely that disabled older persons are at increased risk of oral diseases because of physical disability. As the disability may affect the ability to maintain their oral hygiene and will also restrict their access to receive dental treatment. There are several reliable and valid instruments developed to measure functional ability. A distinction should be made between mobility (walking), physical activities of daily living (PADL, dressing, and bathing) and more complex instrumental activities of daily living (IADL, housekeeping, and shopping) [3]. Among the institutionalized elderly adults, it would be inappropriate if PADL is taken as everybody living in the old age homes may not be capable of performing PADL or even IADL in that case as it is performed mostly by women. Thus, it is recommended to focus on measures of mobility to measure functional ability among institutionalized older adults. Very little is known about the oral health needs of institutionalized older adults who are functionally dependent or their access to oral health care.
The objectives of this study were first, to assess the oral health needs of the institutionalized elders, second to assess their functional ability, third to assess their barriers in accessing oral health care and the utilization of the same among the inmates of old age home of Hyderabad city. And a fourth objective was to determine the association between the functional ability of these vulnerable and dependent population with their utilization of oral health services.

\section{Materials and Methods}

A cross-sectional epidemiological study was conducted among the inmates of old age homes of Hyderabad from a period of 6 months from $25^{\text {th }}$ December to $26^{\text {th }}$ May 2017. The participants aged 55 and above living in the old age homes of Hyderabad were included. Ethical clearance was obtained from Institutional Review Board of Sri Sai College of Dental Surgery, Vikarabad, Telangana. Informed verbal consent was taken from the participants. The participants were informed that their participation in the study will be anonymous, voluntary and not compulsory. A pilot study was done to determine the feasibility of the study and assess the sample size.

Simple random sampling was done for the selection of old age homes. A list of old age homes in Hyderabad city was obtained from the collectorate office of Telangana. Out of the 54 old age homes, 12 have given the permissions to conduct the study Participants who are not in a position to answer were excluded.

*Corresponding author: Nakka Deepthi, MDS, Sri Sai College of Denta Surgery, Public Health Dentistry, Vikarabad, Telangana, 501102, India, E-mail: deepthipaul93@gmail.com

Received November 17, 2018; Accepted November 25, 2018; Published November 30, 2018

Citation: Reddy PP, Anjum MS, Rao KY, Monica M, Akula S, et al. (2018) Assessment of Oral Health Needs, Functional Ability, Barriers and Utilization of Ora Health Services among the Inmates of Old Age Homes of Hyderabad. Dentistry 8 : 521. doi:10.4172/2161-1122.1000521

Copyright: $\odot 2018$ Reddy PP, et al. This is an open-access article distributed under the terms of the Creative Commons Attribution License, which permits unrestricted use, distribution, and reproduction in any medium, provided the original author and source are credited. 
Citation: Reddy PP, Anjum MS, Rao KY, Monica M, Akula S, et al. (2018) Assessment of Oral Health Needs, Functional Ability, Barriers and Utilization of Oral Health Services among the Inmates of Old Age Homes of Hyderabad. Dentistry 8: 521. doi:10.4172/2161-1122.1000521

Page 2 of 3

\begin{tabular}{|c|c|c|}
\hline Demographic details & Frequency & Percentage \\
\hline Age groups & & \\
\hline $55-65$ & 104 & $32 \%$ \\
\hline $66-75$ & 142 & $44 \%$ \\
\hline 76 and above & 77 & $24 \%$ \\
\hline Gender & & \\
\hline Male & 90 & $28 \%$ \\
\hline Female & 233 & $72 \%$ \\
\hline Profession & & \\
\hline Unemployed & 24 & $7.4 \%$ \\
\hline Unskilled & 172 & $53.3 \%$ \\
\hline Skilled & 39 & $12.1 \%$ \\
\hline Driver/farmer/shop owner & 62 & $19.2 \%$ \\
\hline Professional & 26 & $8 \%$ \\
\hline
\end{tabular}

Table 1: Distribution of data based on age, gender and education.

\begin{tabular}{|c|c|c|}
\hline & Frequency & Percentage \\
\hline Past Dental problem & & \\
\hline Yes & 281 & $87 \%$ \\
\hline No & 42 & $13 \%$ \\
\hline Dental problem & & \\
\hline Decay/tooth ache & 115 & $35.6 \%$ \\
\hline Malodour & 16 & $5 \%$ \\
\hline Missing teeth & 72 & $22.3 \%$ \\
\hline Gum problems & 16 & $5 \%$ \\
\hline Swelling & 14 & $4.3 \%$ \\
\hline Loose teeth & 42 & $13 \%$ \\
\hline I don't have any problem & 42 & $13 \%$ \\
\hline Others & 6 & $1.9 \%$ \\
\hline Treatments received & & $21.6 \%$ \\
\hline Yes & 70 & $78.3 \%$ \\
\hline No & 253 & \\
\hline
\end{tabular}

Table 2: Distribution of data based on utilization of dental services.

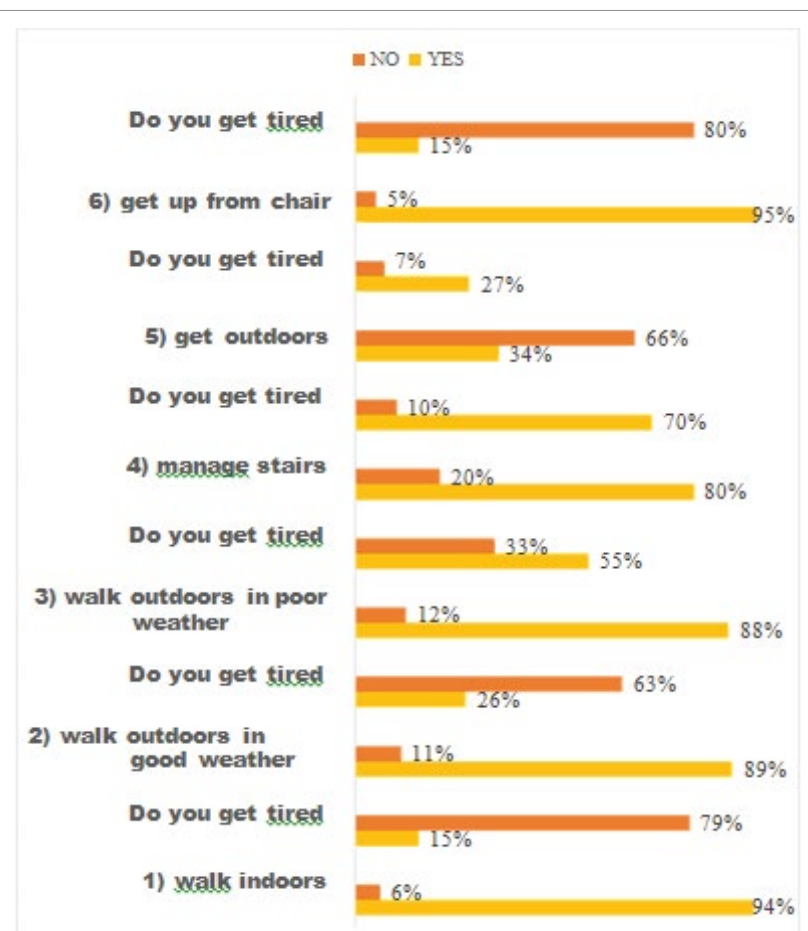

Figure 1: Distribution of need for help and tiredness using functional ability questionnaire by Kirsten Avlund.

For the collection of data, a specially designed questionnaire was developed based on the previous literature and then translated to regional language Telugu. The questionnaire had two components. The first part consisted of demographic details and questions about barriers and utilization of dental services and the second part consisted of questions which assessed the functional ability. Information from the individuals was collected by interview method as most of the individuals were illiterate and was not in a position to read and answer the questionnaire. WHO 1997 dentition status was recorded via visual clinical examination with aid of a mouth mirror and a CPITN probe.

Functional ability was measured by two subscales of the Kirsten Avlund functional ability scale: The Mob-T Scale on tiredness in relation to mobility and the Mob-H Scale about the need for help in relation to mobility. The scales are formed by answers to questions about the following six activities: (1) transfer, (2) walk indoors, (3) get outdoors, (4) walk outdoors in nice weather, (5) walk outdoors in poor weather, and (6) climb stairs. Response categories describe two dimensions:

(1) with or without tiredness afterward and (2) with or without the need of help. The Mob-T Scale counts the number of items performed without tiredness (range 0-6). The Mob-H Scale counts the number of items managed without help (range 0-6). High scale values thus describe the better function. In the present analysis, the scales were dichotomized into those with good function (score 6) and poorer function (score 0-5) [4].

The results obtained were subjected to statistical analysis. SPSS version 20 was used to calculate the statistical analysis. Chi-square test was done to estimate the association with functional ability and the utilization of dental services among the elderly adults of old ages in Hyderabad. (p-value $<0.05$ )

\section{Results and Discussion}

A total of 323 participated, $28 \%$ were males and $72 \%$ were females. The mean age of the population was $60 \pm 5$ years. Among the participants $9 \%$ were married, $10 \%$ were unmarried and $81 \%$ were widow. About $87 \%$ reported that they have been experiencing a dental problem at some point in their life. Among $87 \%$ who reported that they experienced a dental problem, only $22 \%$ received treatments.

Toothache and decay were most commonly remembered dental problems, and medication (16\%) was most commonly received treatment followed by extraction (11\%). Most commonly reported barrier was reported to be limited access to dental care (48\%) and 25\% felt there is no need for treatment in spite of having a dental problem.

About $20 \%$ had better functional ability. There was significant association found $(0.00)$ between age and functional ability. There was no significant association found between gender and functional ability (0.6). There was no significant association found between the functional ability of the old age person and their utilization of oral health services (0.4). A significant level of association was found (0.003) between barriers of accessing oral health services and functional ability. Functional ability is the actual/potential capacity of an individual to perform the activities and tasks that can be normally expected. As the age increases, the functional ability of an individual decrease.

The goal was to reach the unreached group of the population like the people living in old age homes as in this study, where the dental needs of the elderly are changing and growing. A toothache and decay $(35 \%)$ were most commonly remembered dental problems, and medication (16\%) was most commonly received treatment followed by 
Citation: Reddy PP, Anjum MS, Rao KY, Monica M, Akula S, et al. (2018) Assessment of Oral Health Needs, Functional Ability, Barriers and Utilization of Oral Health Services among the Inmates of Old Age Homes of Hyderabad. Dentistry 8: 521. doi:10.4172/2161-1122.1000521

extraction (11\%). It's the tendency of the people not to visit a dentist unless they have pain.

In this study, more than half of the study participants have never been to a dentist (78\%) as there was no availability of dental care at the old age home which could be the reason for having more number of decay among them. And the rest, who visited the dentist, had their last visit more than 3 years back (14\%). Among the participants who had experienced the dental problem $(87 \%)$, only $22 \%$ received treatments.

The utilization of dental services is poor as most of them feel it is unwanted and spending on dental treatment would be a burden for their children in the old age. The results found that limited access to oral health services was the most common barrier reported (48\%). In a study conducted by Bommireddy, et al. fear of dental treatments was the reported barrier [5]. Though old age homes have the provision of having a medical doctor visiting once a week or once a month, they hardly have any dentist visiting at least once in 6 months. According to the study conducted by Strayer, et al. paying for dental care, transportation difficulties, and poor health were the most frequently identified barriers that limited access to oral health care [6]. Fear of dental injection, cost of treatment, feeling of insecurity when the dentist is operating and disturbing noise from dental drill were the major barriers experienced by the people of Ibadan, Saudi Arabia irrespective of the age according to study conducted by Ajayi, et al. [7].

Only $20 \%$ had better functional ability (Mob-H scale) whereas according to the Mob-T scale only $0.9 \%$ was least tired. A significant difference in functional ability was found between participants from a different age. There was no significant association found between the functional ability of the study participants and utilization of oral health services whereas Avlund, et al. found a significant association. This result could be because they give less importance to oral health [8-10] (Tables 1 and 2 and Figure 1).

\section{Conclusion}

Elderly people after making great contributions to the development of the community must not be considered as a burden. Elderly people have not visited a dentist in spite of having a dental problem that leads to more decay in the participants. The functional ability had no significant impact of their utilization of the dental services. This shows their attitude toward oral health. Newer oral health policies should be made for the elderly. There is a need for oral health promotion and intervention in these high-risk populations to bring about a change in their oral health status by utilizing dental services towards the better [11-14].

\section{References}

1. Petersen PE, Yamamoto $T$ (2005) Improving the oral health of older people: the approach of the WHO Global Oral Health Programme. Community Dent Oral Epidemiol 33: 81-92.

2. Shaheen SS, Kulkarni S, Doshi D, Reddy S, Reddy P (2015) Oral health status and treatment need among institutionalized elderly in India. Indian J Dent Research 26: 493-499.

3. Avlund K, Kreiner S, Schultz-Larsen K (1996) Functional ability scales for the elderly. Eur J Public Health 6: 35-42.

4. Avlund, K, Holm-Pedersen $P$, Schroll M (2001) Functional ability and oral health among older People: a longitudinal study from age 75 to 80. JAGS 49: 954-62.

5. Bommireddy VS, Koka KM, Pachava S, Chandu VC (2016) Dental service utilization: Patterns and barriers among rural elderly in Guntur district, Andhra Pradesh. J Clin Diagn Res 10: 43-47.

6. Strayer MS (1995) Perceived barriers to oral health care among the homebound Special Care in Dentistry 15: 113-118.

7. Ajayi DM, Arigbede AO (2012) Barriers to oral health care utilization in Ibadan, South West Nigeria. Afr health Sci 12: 507-513.

8. Avlund K, Damsgaard MT, Sakari-Rantala R, Laukkanen P, Schroll M (2002) Tiredness in daily activities among nondisabled old people as determinant of onset of disability. J Clin Epidemiol 55: 965-973.

9. Bharti R, Chandra A, Tikku AP, Arya D, Gupta R (2015) Oral care needs, barriers and challenges among elderly in India. J Indian Prosthodont Soc 15: $17-22$.

10. Hoben M, Hu H, Xiong T, Kent A, Kobagi N, et al. (2016) Barriers and facilitators in providing oral health care to nursing home residents, from the perspective of care aides-a systematic review protocol. Systematic reviews 5: 53 .

11. Bruhl A, Avlund K (2012) Validity and internal consistency of mobility scales for healthy older people in Germany. J Clin Gerontol Geriatr 3: 29-35.

12. Raja BK, Radha G, Rekha R, Pallavi SK (2015) Oral health status of institutionalized elder's: A Systematic Review. Int J Oral Health Med Res 2: 86-91.

13. De Lurdes PM, Oliveira L, Lunet N (2014) Caries and oral health related behaviours among homeless adults from Porto, Portugal. Oral Health Prev Dent 12.

14. Al-Shehri SA (2012) Oral health status of older people in residential homes in Saudi Arabia. OJST 2: 307-313. 